\title{
Panoramic radiograph - a useful tool to assess the difficulty in extraction of third molars
}



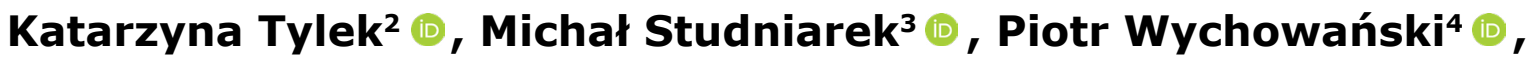 \\ Magdalena Kaczoruk-Wieremczuk1 ${ }^{\circledR}$, Dorota Pyrzowska1 ${ }^{\circledR}$,

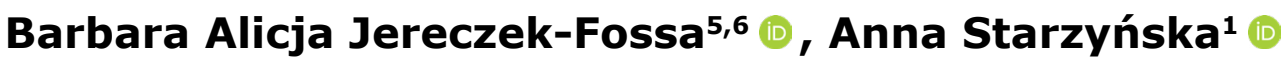

${ }^{1}$ Department of Oral Surgery, Medical University of Gdańsk, Poland

${ }^{2}$ Student Scientific Circle at the Department of Oral Surgery, Medical University of Gdańsk, Poland

${ }^{3}$ Department of Radiology I, Medical University of Gdańsk, Poland

${ }^{4}$ Department of Oral Surgery, Medical University of Warsaw, Poland

${ }^{5}$ Division of Radiotherapy, IEO European Institute of Oncology, Italy

${ }^{6}$ Department of Oncology and Hematooncology, University of Milan, Italy

\begin{abstract}
Introduction: Third molars (TMs) are the most frequently impacted teeth due to the frequent lack of space in the dental arch resulting in their malposition or inability to erupt. Partially erupted TMs that cause recurrent inflammatory conditions must be removed. The aim of this study was to assess TM position on panoramic radiographs. Materials and methods: We evaluated 200 panoramic radiographs of patients 18-72 years of age. Teeth were assessed in terms of the presence of dental follicle, cervix/root ratio and root development stage. Maxillary TMs were assessed using the Archer and Pell and Gregory classifications, whereas the mandibular ones according to Pell and Gregory, Winter, IAN and Pederson classifications. Results: 622 TMs were assessed. In the maxilla, the most common type was A-positioned, vertically angulated TM with completely formed root/roots. In the mandible, the most common type was A1-positioned, mesioangular TM with completely formed root/roots and without enlarged follicle. According to Pederson's index, 59.44\% TMs were moderately difficult to extract. Most roots were in contact with inferior alveolar nerve. Conclusions: The use of the classifications mentioned above is helpful in assessment of the surgery difficulty level. In the long term this allows to increase the predictability of the procedure and minimize the intra- and post-operative complications.
\end{abstract}

Keywords: Archer classification · Pell and Gregory classification · IAN classification · Pederson scale · Winter classification

\section{Citation}

Adamska P, Adamski ŁJ, Musiał D, Tylek K, Studniarek M, Wychowański P, Kaczoruk-Wieremczuk M, Pyrzowska D, Jereczek-Fossa BA, Starzyńska A. Panoramic radiograph - a useful tool to assess the difficulty in extraction of third molars. Eur J Transl Clin Med. 2020;3(2):44-52.

DOI: $10.31373 /$ ejtcm/126928 


\section{Introduction}

Third molars (TMs) are the most frequently impacted teeth due to the frequent lack of space in the dental arch results in their malposition or inability to erupt. This promotes pericoronitis (operculitis), root resorption in second molars, dental caries, pulpitis, periodontitis, osteitis or ulcerative stomatitis. For these and other reasons the TMs often have to be extracted. The pantomographic radiograph is a basic tool used to evaluate the position of the TMs before the procedure [1-3]. The aim of this paper was to evaluate the TMs on panoramic radiographs using selected indicators.

\section{Materials and methods}

The study group included 200 patients, $18-72$ years of age, who were treated at a single instutution in Gdańsk (Poland) in the years 2018-2019. The inclusion criteria were: having at least one TM, lack of chronic diseases, not taking any medication. Informed consent was obtained from all the participants and their anonymity was preserved.

Teeth were assessed in terms of the root formation stage (complete or incomplete root development; Fig. 1), cervix/root ratio (roots spaced more widely than the cervix, cervix diameter larger than the width of the roots or width of the roots equal to the diameter of the cervix; Fig. 2) and occurrence of enlarged follicle (Fig. 3). Upper teeth were assessed using the Archer (Fig. 4) and Pell and Gregory classification (Fig. 5). The relation of the lower TMs to the inferior alveolar nerve was assessed using the IAN (inferior alveolar nerve) classification (Fig. 6). Teeth angulation was assessed using the Winter (Fig. 7) and the Pell and Gregory classifications (Fig. 8 and 9), as well as the Pederson index (Table 1) [4-14].

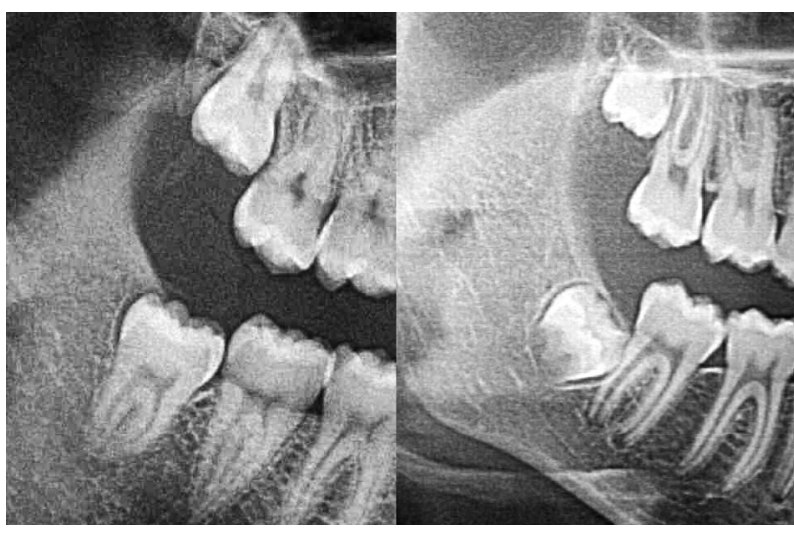

$1 \mathrm{~A}$

1B

Figure 1. Roots development (lower third molars - right side) A. complete; B. incomplete roots development
Table 1. Difficulty level prediction for impacted mandibular third molar removal - Pederson scale

\begin{tabular}{|c|c|}
\hline \multicolumn{2}{|c|}{ Score } \\
\hline \multicolumn{2}{|c|}{ Spatial relationship } \\
\hline Mesioangular & 1 \\
\hline Horizontal/ & 2 \\
\hline transverse & 3 \\
\hline Vertical & $\mathbf{3 - 4}$ \\
\hline Distoangular & $\mathbf{5 - 6}$ \\
\hline \multicolumn{2}{|c|}{ difficult } \\
\hline Level A
\end{tabular}

TM - third molar; level A - the occlusal plane of the TM is at the same level as the occlusal plane of the second molar; level B - the occlusal plane of the TM is between the occlusal plane and the cervical margin of the second molar; level $\mathrm{C}-$ the occlusal level of the TM is below the cervical margin of the second molar; class $I$ - there is sufficient amount of space between the anterior border of the ramus and the distal part of the second molar for the mesiodistal diameter of the TM crown; class II - the space between the anterior border of the ramus and the distal part of the second molar is less than the mesio-distal diameter of the TM crown; class III - most part or all of the TM is located within the ramus 


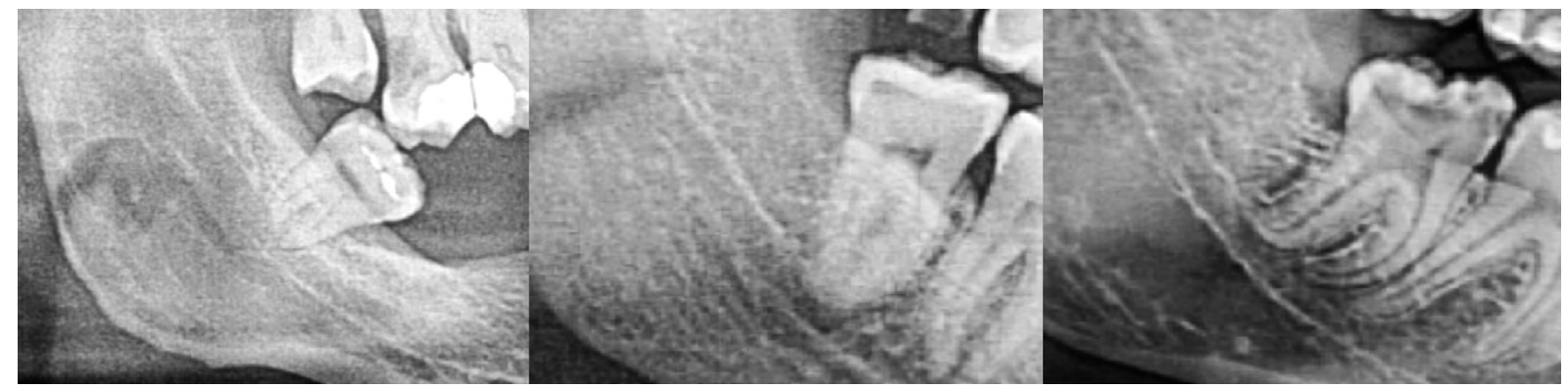

2A

2B

2C

Figure 2. Cervix/root ratio (lower third molars - right side)

A. cervix diameter larger than the width of the roots; B. width of the roots equal to the diameter of the cervix; C. roots spaced more widely than the cervix

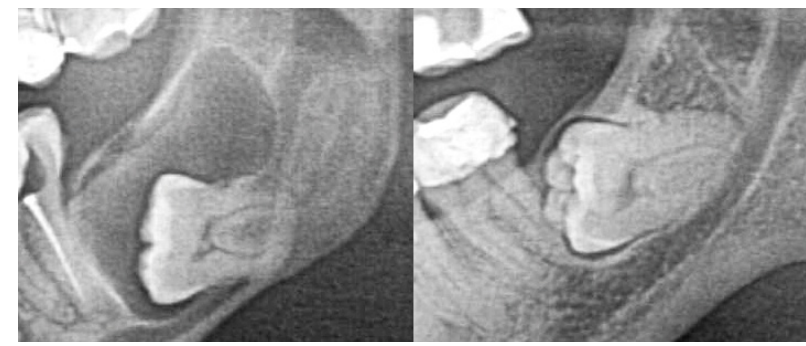

3A

Figure 3. Dental follicle (lower third molars - left side)

A. enlarged follicle; B. non-enlarged follicle

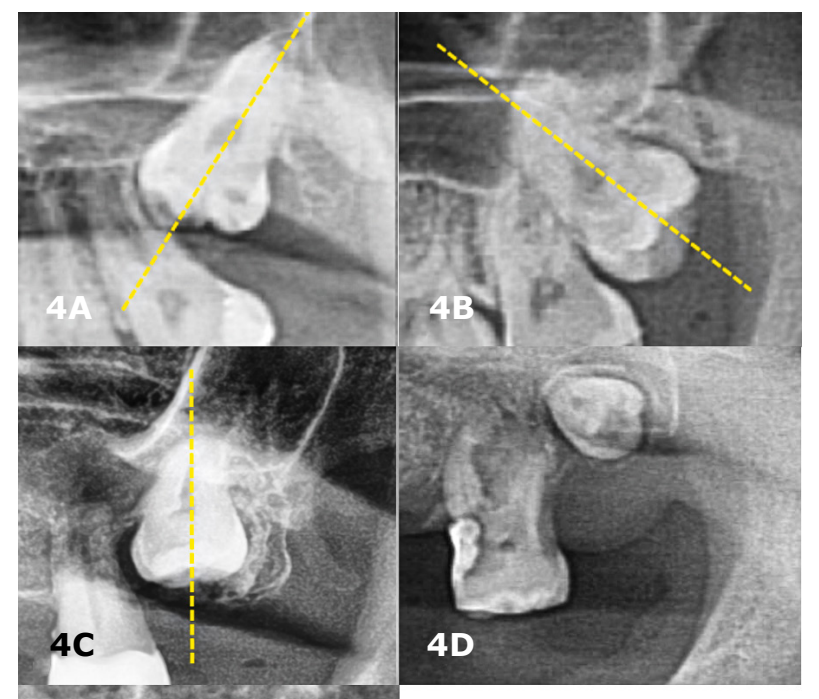

Figure 4. Archer-Kruger classification (upper third molars - left side)

A. mesioangular;

B. distoangular;

C. vertical;

D. buccoangular;

E. linguoangular

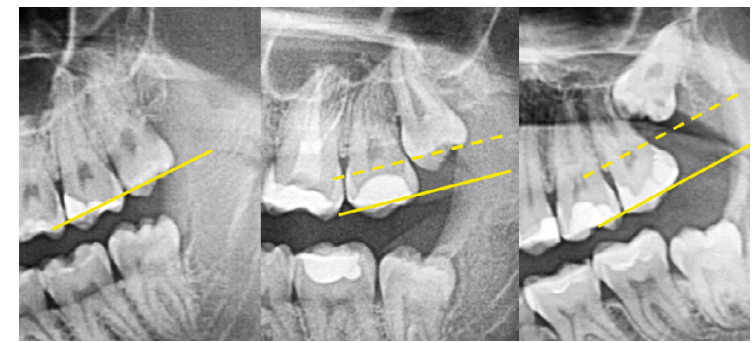

5A

5B

5C

Figure 5. Pell and Gregory classification for the maxilla (upper third molars - left side) A. level A; B. level B; C. level C

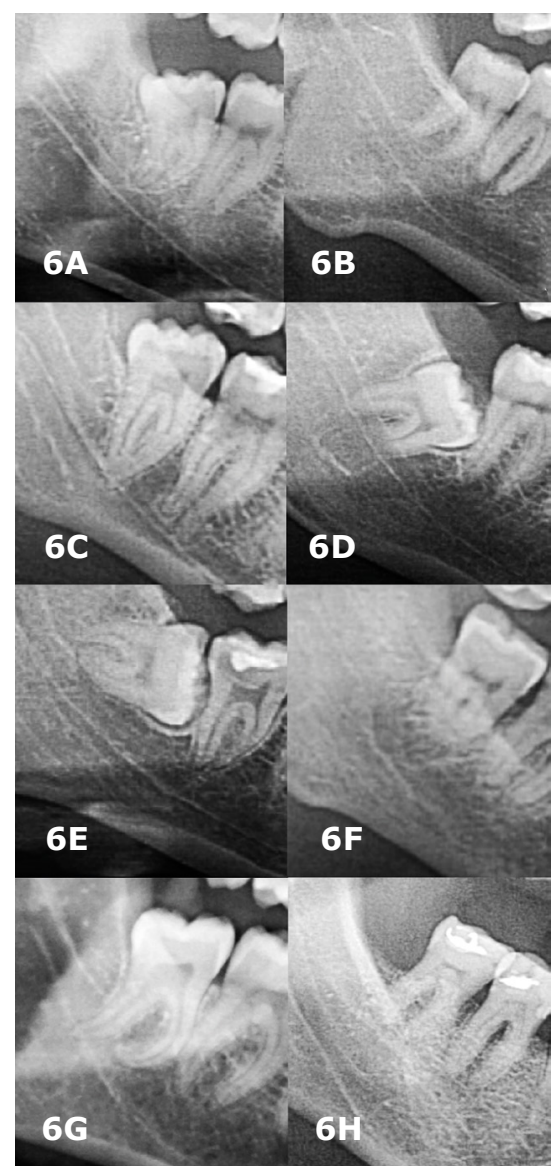

Figure 6. IAN classification (lower third molars - right side) A. darkening of roots; B. deflection of roots; C. narrowing of roots; D. dark and bifid apex of roots; E. interruption of white line of the canal; F. diversion of canal; G. narrowing of the canal; H. no relationship 

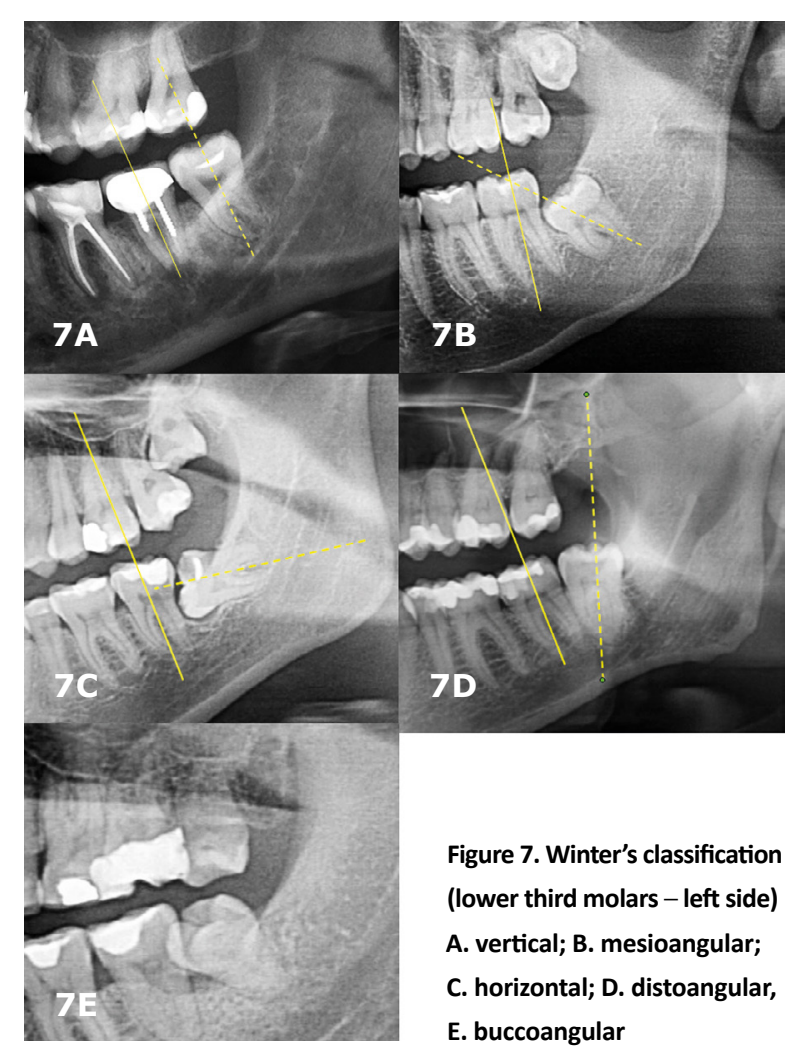

Figure 7. Winter's classification (lower third molars - left side) A. vertical; B. mesioangular; C. horizontal; D. distoangular, E. buccoangular



Figure 9. Pell and Gregory classification for the mandible (lower third molars - left side)

A. level A; B. level B;

C. level C
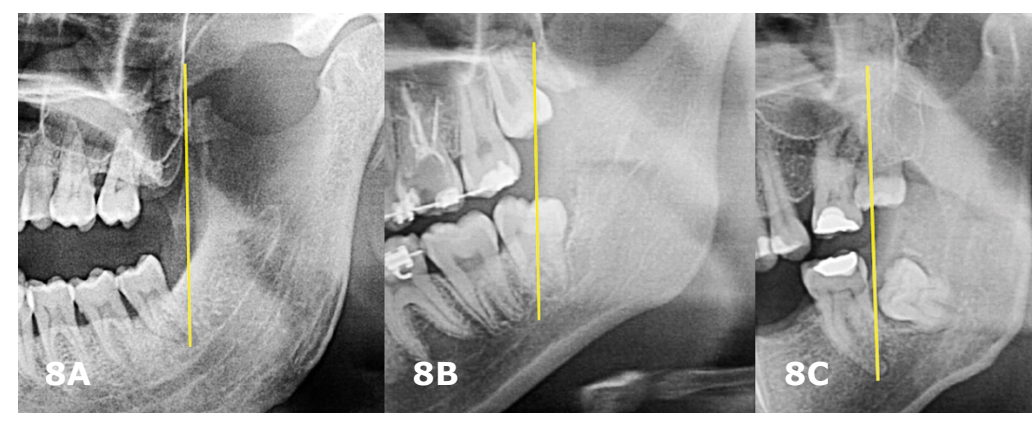

Figure 8. Pell and Gregory classification for the mandible (lower third molars - left side) A. class I; B. class II; C. class III
Statistical analysis was performed using the STATISTICA 13.3 (StatSoft Inc. Tulsa, United States) licensed by the Medical University of Gdańsk. All tests were considered statistically significant at $p \leq 0.05$. Normal distribution of the analysed variables was verified with the Shapiro-Wilk test. Non-parametric tests were used to evaluate the scales (Mann-Whitney, Wilcoxon and Spearman correlation tests).

\section{Results}

Of the total evaluated 622 TMs, 299 were in the maxilla and 323 in the mandible. In the maxilla, most TMs were type $A$ according to the Pell and Gregory classification ( $n=158 ; 52.84 \%$ ), vertically angulated ( $n=210 ; 70.23 \%$ ) according to the Archer classifi- cation and with complete root formation ( $\mathrm{n}=216$; 72.24\%; Table 2 and 3). Whereas in the mandible most TMs were type $A 1$ ( $n=143 ; 44.30 \%$ ), mesioangular ( $n=164 ; 50.77 \%$ ), with complete root development ( $n=248 ; 76.80 \%)$ and without enlarged follicle ( $n=$ $274 ; 84.83 \%)$. Most roots (61.99\%) were in contact with the inferior alveolar nerve (IAN classification) and the most common type was the one with dark and bifid apices. According to Pederson's scale, 59.44\% of the TMs were moderately difficult to remove. Pederson's scale identified significant differences within the Pell and Gregory classification (position A1 significantly differs from A2, C2, B2, C3 and C1 ones). Evaluating the median within individual groups, it can be shown that the molars with the most difficulty (according to Pederson scale) belonged to $C 3, B 3$ and $A 3$ groups; followed by B2, C2, A2 and C1, B1, A1 (Tables 2 and 4). 
Table 2. Assessment of root development and enlarged follicle of third molars

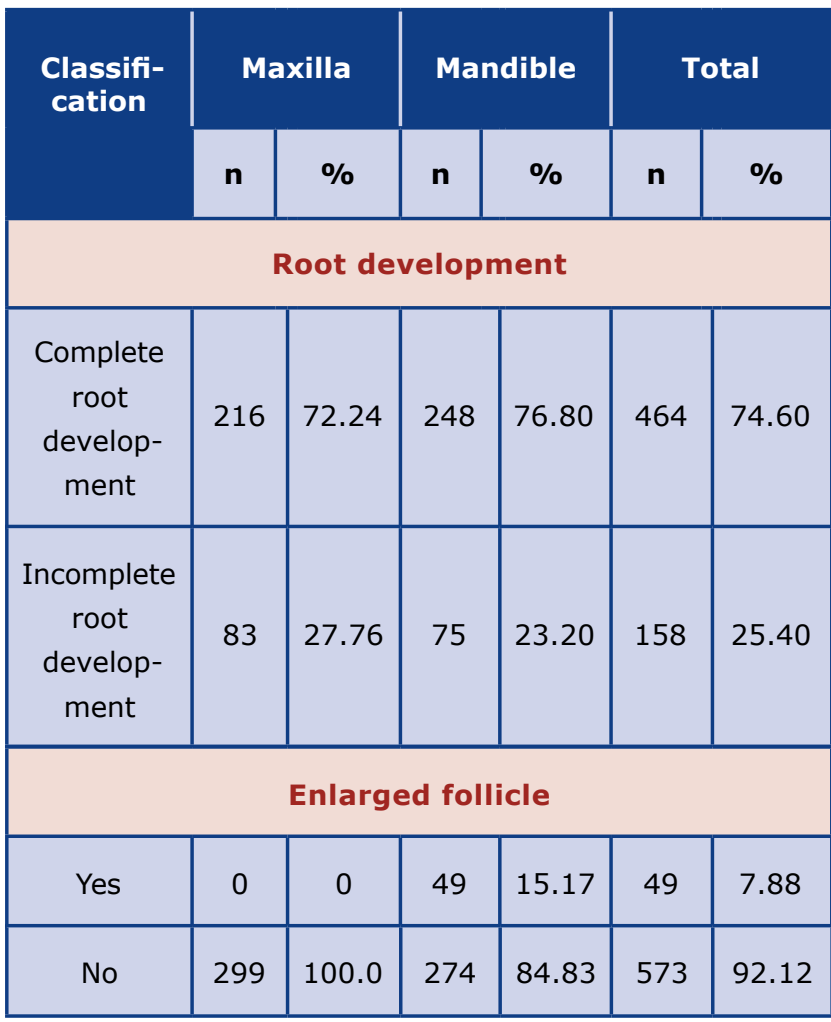

The studied population of patients was not normally distributed (Shapiro-Wilk's test). The Spearmanrank correlation coefficient revealed a relationship between the higher scores in the Pederson scale and the IAN classification, complete root development and roots spaced more widely than the cervix. The more complicated and difficult the position according to the Pederson scale, the higher the risk of the inferior alveolar nerve injury. The relationship between the complete root development and the Pearson index indicates that it is more difficult to remove the tooth with completely formed roots and with roots spaced more widely than the cervix.

\section{Discussion}

The stage of root development is of significance during the TM extraction procedure. The root formation process may be classified as complete or incomplete. It is assumed that the shorter the roots, the easier the extraction. Roots spaced more widely than the cervix suggest more difficulties during procedure when compared with more tapered roots. Enlarged follicle may facilitate tooth extraction [4-14]. The Archer classification is based on the analysis of the incli-
Table 3. Assessment of third molars in the maxilla

\begin{tabular}{|c|c|c|}
\hline \multirow[t]{2}{*}{ Classification } & \multicolumn{2}{|c|}{ Maxilla } \\
\hline & $\mathbf{n}$ & $\%$ \\
\hline \multicolumn{3}{|c|}{ Archer and Kruger classification } \\
\hline Mesioangular & 26 & 8.70 \\
\hline Distoangular & 39 & 13.04 \\
\hline Vertical & 210 & 70.23 \\
\hline Horizontal & 1 & 0.33 \\
\hline Buccoangular & 21 & 7.02 \\
\hline Linguoangular & 2 & 0.67 \\
\hline Inverted & 0 & 0 \\
\hline \multicolumn{3}{|c|}{ Pell-Gregory classification } \\
\hline Level A & 158 & 52.84 \\
\hline Level B & 38 & 12.71 \\
\hline Level C & 103 & 34.45 \\
\hline
\end{tabular}

TM - third molar; level A - the occlusal plane of the TM is at the same level as the occlusal plane of the second molar; level $B$ - the occlusal plane of the TM is between the occlusal plane and the cervical margin of the second molar; level $\mathrm{C}$ - the occlusal level of the TM is below the cervical margin of the second molar

nation of the long axis of the TM to the second molar in the maxilla. This classification features mesioangular, distoangular, vertical, horizontal, buccoangular, linguoangular and inverted positions. Similarly, Winter's classification is based on the analysis of the inclination of the long axis of the TM to the second molar in the mandible and features mesioangular, distoangular, vertical, horizontal, buccoangular, linguoangular and inverted positions [9-10]. Neither of these two classifications includes the assessment of the TM relation to the occlusal plane (Archer and Winter classifications) and the Winter classification doesn't take cognisance of the relation of the TM to the ramus of the mandible. The Pell and Gregory index supplements Winter and Archer's shortcomings by evaluating the TM rela- 
Table 4. Assessment of third molars in the mandible

\begin{tabular}{|c|c|c|}
\hline \multirow[t]{2}{*}{ Classification } & \multicolumn{2}{|c|}{ Maxilla } \\
\hline & $\mathbf{n}$ & $\%$ \\
\hline \multicolumn{3}{|l|}{ Cervix/root ratio } \\
\hline Roots spaced more widely than the cervix & 116 & 35.84 \\
\hline Cervix diameter larger than the roots & 76 & 23.53 \\
\hline Width of the roots equal to the diameter of the cervix & 111 & 34.30 \\
\hline Less than $50 \%$ of the root is formed - impossible assessment & 20 & 6.33 \\
\hline \multicolumn{3}{|l|}{ Winter classification (for mandible) } \\
\hline Mesioangular & 164 & 50.77 \\
\hline Distoangular & 97 & 30.03 \\
\hline Vertical & 29 & 8.98 \\
\hline Horizontal & 16 & 4.95 \\
\hline Buccoangular & 16 & 4.95 \\
\hline Linguoangular & 1 & 0.31 \\
\hline Inverted & 0 & 0 \\
\hline \multicolumn{3}{|l|}{ Pell-Gregory classification } \\
\hline Level A & 189 & 58.51 \\
\hline Level B & 71 & 21.98 \\
\hline Level C & 63 & 19.50 \\
\hline Class 1 & 182 & 56.35 \\
\hline Class 2 & 119 & 36.84 \\
\hline Class 3 & 22 & 6.81 \\
\hline $\mathrm{A} 1$ & 143 & 44.27 \\
\hline $\mathrm{A} 2$ & 43 & 13.31 \\
\hline A3 & 3 & 0.93 \\
\hline B1 & 27 & 8.35 \\
\hline
\end{tabular}




\begin{tabular}{|c|c|c|}
\hline \multirow[t]{2}{*}{ Classification } & \multicolumn{2}{|c|}{ Maxilla } \\
\hline & $\mathbf{n}$ & $\%$ \\
\hline \multicolumn{3}{|l|}{ Pell-Gregory classification } \\
\hline B2 & 41 & 12.69 \\
\hline B3 & 3 & 0.93 \\
\hline $\mathrm{C} 1$ & 12 & 3.72 \\
\hline $\mathrm{C} 2$ & 35 & 10.84 \\
\hline $\mathrm{C} 3$ & 16 & 4.95 \\
\hline \multicolumn{3}{|c|}{ The TM in relation to inferior alveolar nerve } \\
\hline Darkening of roots & 26 & 8.05 \\
\hline Deflection of roots & 24 & 7.43 \\
\hline Narrowing of roots & 7 & 2.17 \\
\hline Dark and bifid apex of roots & 86 & 23.63 \\
\hline Interruption of white line of canal & 28 & 8.67 \\
\hline Diversion of canal & 20 & 6.19 \\
\hline Narrowing of canal & 6 & 1.86 \\
\hline No relation with canal & 126 & 39.01 \\
\hline \multicolumn{3}{|l|}{ Pederson classification } \\
\hline Very difficult & 72 & 22.29 \\
\hline Moderately difficult & 192 & 59.44 \\
\hline Minimally difficult & 59 & 18.27 \\
\hline
\end{tabular}

TM - third molar; level A - the occlusal plane of the TM is at the same level as the occlusal plane of the second molar; level B - the occlusal plane of the TM is between the occlusal plane and the cervical margin of the second molar; level C - the occlusal level of the TM is below the cervical margin of the second molar; class I - there is sufficient amount of space between the anterior border of the ramus and the distal part of the second molar for the mesiodistal diameter of the TM crown; class II - the space between the anterior border of the ramus and the distal part of the second molar is less than the mesio-distal diameter of the TM crown; class III - most part or all of the TM is located within the ramus 
tionship to the occlusal surface of the adjacent second molar and to the anterior border of the ramus of the mandible. In the maxilla, the Pell and Gregory classification evaluates only the relationship to the occlusal surface of the adjacent second molar and the assessment is analogous to the one in the mandible. The IAN classification allows to predict the possible alveolar nerve injury, based on a pantomographic examination. Darkening, deflection or narrowing of roots, dark and bifid apices, interruption of white line of the canal as well as diversion or narrowing of the canal are associated with the risk of postsurgical paraesthesia [4-9].

Several studies suggest that some local and general factors can influence the degree of difficulty associated with the surgical TM removal [10-11, 15-19]. Factors and features contributing to the facilitation of TM removal include: mesioangular impaction, class I and level A according to the Pell and Gregory classification, fused roots that are not in contact with the mandibular canal, incomplete impaction, tapered roots at no point spaced more widely that the diameter at the level of the cervix, incomplete root development, large dental follicle, wide periodontal ligament space and high elastic modulus of the bone. The last two features are more commonly present in younger patients [10-11, 15-19]. Factors and features rendering the extraction procedure difficult are: distoangular impaction, class III and level $\mathrm{C}$ according to Pell and Gregory classification, curved roots, complete impaction, roots spaced more widely than the cervix, TM in contact with the second molar or in close proximity to the mandibular canal, complete root development, narrow dental follicle, narrow periodontal ligament space and low elastic modulus of bone. Narrow periodontal ligament space and lower elastic modulus of bone are common in elderly patients [10-11, 15-19].

Yuasa et al. distinguished nine factors that may be of clinical significance while removing a TM (depth, abnormal root curvature, width of roots, number of roots, ramus relationship/space available, proximity to the mandibular canal, periodontal membrane space, relative horizontal position of the third molar) and examined them using univariate and multivariate analysis [12]. Depth, ramus relationship/space available and width of root had impact on the degree of difficulty associated with the surgery. Abnormal root curvature and relative horizontal position of the third molar were not statistically significant [12].

Carvalho et al. emphasized that patient's sex, age or BMI index do not affect the degree of difficulty. However, age does play a role in the event of postoperative complications [15]. Eyricha et al. analysed retrospectively cone beam computed tomography scans performed before the TMs extractions and demonstrated that the two independent factors leading to the postoperative impairment of the inferior alveolar nerve function are narrowing of the IAN canal and direct contact between the IAN and the root [20].

\section{Conclusions}

The above- mentioned classifications are useful when assessing the degree of difficulty associated with the TM extraction surgery. In the long term, such an assessment may increase the predictability of the procedure and to minimize the intra- and post-operative complications. All of the described classifications have limitations due to the fact that they do not take into account all the significant features of TMs. In order to evaluate the risk of the intra- and post-operative complications and to plan the procedure properly, all the classifications mentioned above should be taken into account prior to the surgery.

\section{References}

1. Ali AS, Benton JA, Yates JM. Risk of inferior alveolar nerve injury with coronectomy vs surgical extraction of mandibular third molars - a comparison of two techniques and review of the literature. J Oral Rehabil [Internet]. 2018;45(3):250-7. Available from: https://doi.org/10.1111/joor.12589

2. La Monaca G, Vozza I, Giardino R, Annibali S, Pranno N, Cristalli MP. Prevention of neurological injuries during mandibular third molar surgery: technical notes. Ann Stomatol (Roma) [Internet]. 2017 Nov 8;8(2):45-52. Available from: https://doi. org/10.11138/ads/2017.8.2.053

3. Ryalat S, AIRyalat SA, Kassob Z, Hassona Y, Al-Shayyab MH, Sawair F. Impaction of lower third molars and their association with age: radiological perspectives. BMC Oral Health [Internet]. 2018;18(1):58. Available from: https://doi.org/10.1186/ $\underline{\text { s12903-018-0519-1 }}$

4. Juodzbalys G, Daugela P. Mandibular third molar impaction: review of literature and a proposal of a classification. J oral Maxillofac Res [Internet]. 2013 Jul 1;4(2):e1-e1. Available from: https://doi.org/10.5037/jomr.2013.4201

5. Lim AAT, Wong CW, Allen JC. Maxillary Third Molar: Patterns of Impaction and Their Relation to Oroantral Perforation. J Oral Maxillofac Surg [Internet]. 2012;70(5):1035-9. Available from: https://doi.org/10.1016/i.joms.2012.01.032 
6. Archer WH. Oral and maxillofacial surgery. 5th ed. WB Saunders. 1975. 311 p.

7. Pell GJ. Impacted mandibular third molars: classification and modified techniques for removal. Dent Dig. 1933;39:330-8.

8. Motamedi M. New concepts in impacted third molar surgery by Mohammad Hosein Kalantar Motamedi and Farshid Kavandi. In: A Textbook of Advanced Oral and Maxillofacial Surgery [Internet]. 2013. Available from: http://doi. org/10.5772/3316

9. Winter G. Impacted mandibular third molars. St Louis: American Medical Book Co; 1926. 241-79 p.

10. Khanal P, Dixit S, Singh R, Dixit P. Difficulty index in extraction of impacted mandibular third molars and their post-operative complications. J Kathmandu Med Coll [Internet]. 2014 Aug 12;3(1):14-20. Available from: https://doi.org/10.3126/ jkmc.v3i1.10918

11. García AG, Sampedro FG, Rey JG, Vila PG, Martin MS. Pell-Gregory classification is unreliable as a predictor of difficulty in extracting impacted lower third molars. Br J Oral Maxillofac Surg. 2000;38(6):585-7.

12. Yuasa H, Kawai T, Sugiura M. Classification of surgical difficulty in extracting impacted third molars. Br J Oral Maxillofac Surg. 2002;40(1):26-31.

13. Bali A, Bali D, Sharma A, Verma G. Is Pederson Index a True Predictive Difficulty Index for Impacted Mandibular Third Molar Surgery? A Meta-analysis. J Maxillofac Oral Surg [Internet]. 2013 Sep 22;12(3):359-64. Available from: http://link. springer.com/10.1007/s12663-012-0435-x

14. Diniz-Freitas M, Lago-Méndez L, Gude-Sampedro F, Somoza-Martin JM, Gándara-Rey JM, García-García A. Pederson scale fails to predict how difficult it will be to extract lower third molars. Br J Oral Maxillofac Surg [Internet]. 2007;45(1):23-6. Available from: https://doi.org/10.1016/i.bjoms.2005.12.004

15. Carvalho RWF, do Egito Vasconcelos BC. Assessment of Factors Associated With Surgical Difficulty During Removal of Impacted Lower Third Molars. J Oral Maxillofac Surg. 2011;69(11):2714-21.

16. Susarla SM, Dodson TB. Risk factors for third molar extraction difficulty. J Oral Maxillofac Surg [Internet]. 2004;62(11):136371. Available from: https://doi.org/10.1016/i.joms.2004.05.214

17. Susarla SM, Dodson TB. How well do clinicians estimate third molar extraction difficulty? J Oral Maxillofac Surg [Internet]. 2005;63(2):191-9. Available from: $\underline{\text { https://doi.org/10.1016/i.joms.2004.05.220 }}$

18. Susarla SM, Dodson TB. Estimating third molar extraction difficulty: A comparison of subjective and objective factors. J Oral Maxillofac Surg [Internet]. 2005;63(4):427-34. Available from: https://doi.org/10.1016/j.joms.2004.12.003

19. Tenglikar P, Munnangi A, Mangalgi A, Uddin SF, Mathpathi S, Shah K. An Assessment of Factors Influencing the Difficulty in Third Molar Surgery. Ann Maxillofac Surg [Internet]. 2017;7(1):45-50. Available from: https://doi.org//10.4103/ams. ams 19415

20. Eyrich G, Seifert B, Matthews F, Matthiessen U, Heusser CK, Kruse AL, et al. 3-Dimensional Imaging for Lower Third Molars: Is There an Implication for Surgical Removal? J Oral Maxillofac Surg [Internet]. 2011;69(7):1867-72. Available from: https://doi.org/10.1016/i.joms.2010.10.039 